\title{
Asymptotic state boundaries and peak states in barodesy for clay
}

\section{G. MEDICUS*}

\begin{abstract}
With constant stretching of soil, the memory is gradually swept out and the so-called asymptotic states are reached: asymptotic states are proportional stress paths as well as particular curves in the void ratio against the mean stress plane. The so-called asymptotic state boundary surface (ASBS) serves as a graphical representation for asymptotic states. In contrast to asymptotic states, peak states of drained triaxial tests are states with vanishing stiffness. In this paper, an explicit formulation of the ASBS and peak state envelope of barodesy are introduced. Different clay types are compared with barodesy as well as with predictions by hypoplasticity. The peak states of the experiments confirm the results obtained with barodesy and hypoplasticity. It is shown that different to elastoplastic models, the ASBS does not include peak states in barodesy and hypoplasticity. In addition to standard axisymmetric simulations, investigations are also carried out in the deviatoric plane with the focus on plane strain failure.
\end{abstract}

KEYWORDS: clays; constitutive relations; shear strength

Published with permission by the ICE under the CC-BY 4.0 license. (http://creativecommons.org/licenses/by/4.0/)

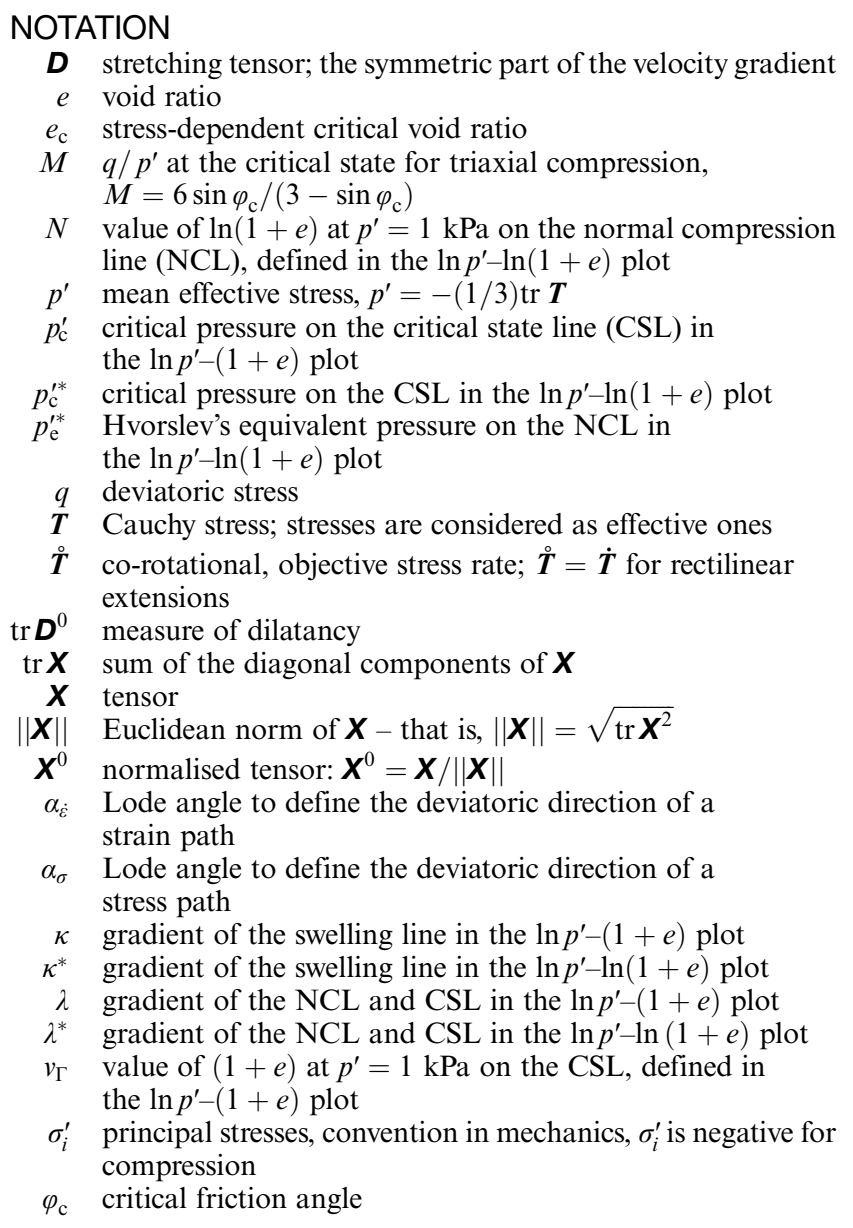

Manuscript received 18 June 2019; first decision 16 January 2020; accepted 17 January 2020.

Published online at www.geotechniqueletters.com on 19 February 2020.

*Unit of Geotechnical and Tunnel Engineering, University of Innsbruck, Austria (Orcid:0000-0002-1197-2345).

\section{INTRODUCTION}

If soil is deformed with constant stretching - that is, a proportional strain path - the resulting stress path approaches asymptotically a proportional stress path (Goldscheider, 1976; Topolnicki et al., 1990; Chu \& Lo, 1994). Gudehus \& Mašín (2009) propose that asymptotic states are asymptotic stress ratios (i.e. proportional stress paths) related with particular curves in the void ratio against the mean stress plane (also compare Wood (1990), Gudehus (2011) and Mašín (2012a)). The volume decreasing proportional strain paths lead to compression asymptotic states and volume increasing proportional strain paths lead to extension asymptotic states, according to Mašín (2012a). The so-called asymptotic state boundary surface (ASBS) includes asymptotic states with respect to stress and void ratio.

The peak states of drained triaxial tests are obtained through a stress path in a fixed direction and are characterised by vanishing stress rate. Different to asymptotic states, stretching is not constant in a drained triaxial test. The locus of peak states is often denoted as part of the state boundary surface (SBS) on the dry side of critical state - for example, see Lancellotta (2009); Barnes (2010) and Atkinson (2007). The concept of the SBS goes back to Roscoe et al. (1958). They considered a surface that includes all possible states with respect to stress and void ratio (e.g. Lancellotta, 2009).

The shapes of the ASBS and the SBS provide a graphical representation to evaluate a constitutive model (Gudehus \& Mašín, 2009; Mašín, 2012a). However, in experimental testing, asymptotic extension states have not been investigated (Mašín, 2013). DEM simulations by Mašín (2012a) show close agreement between peak states of drained triaxial tests and asymptotic extension states. Shi et al. (2017) incorporate a non-linear Hvorslev surface as ASBS into a hypoplastic model assuming that the ASBS includes peak states.

In elastoplastic models - including concepts from critical state soil mechanics - the ASBS serves as a limit surface and thus includes peak states - that is, the ASBS coincides with the SBS (Mašín, 2012a). In hypoplasticity and barodesy, the ASBS is not a limit surface as it is in elastoplastic models. Mašín \& Herle (2005) showed that in hypoplasticity certain 
paths can slightly exceed the ASBS. Other investigations on state boundaries of hypoplastic and elastoplastic models are in Nakai (2007); Pedroso et al. (2005); Lancellotta (2009) and Mašín (2012b, 2013, 2019).

In this paper, the ASBS and the peak envelope of barodesy for clay are introduced. The ASBS of barodesy for clay (Medicus \& Fellin, 2017) is compared with the one of clay hypoplasticity according to Mašín (2013). It is shown that in contrast to elastoplastic models, the ASBS does not include peak states in hypoplasticity and barodesy. The predictions of the peak states with barodesy and hypoplasticity presented here are confirmed by experiments of drained triaxial tests by Atkinson (2007): the peak strength envelope of fully saturated, reconstituted soil is curved with zero strength at vanishing stress (e.g. Krey, 1927; Tiedemann, 1937; Atkinson, 2007; Bergholz \& Herle, 2017). Further investigations are carried out in the deviatoric plane with a focus on plane strain failure. Barodesy captures stress-induced anisotropy and not inherent structural anisotropy. Thus, the shape of the ASBS is independent of the initial stress state and aligned along the hydrostatic axis.

The investigations in this paper on barodesy refer to barodesy for clay. The equations of barodesy for clay are published in Medicus et al. (2016) and Medicus \& Fellin (2017).

\section{STATE BOUNDARIES}

Feasible states are limited with respect to stress $\boldsymbol{T}$ and void ratio $e$. For example, the isotropic normal compression line (NCL) is a boundary of feasible states in the $e-p^{\prime}$ space. The stress ratio $q / p^{\prime}$ for hydrostatic compression is zero. At critical states under triaxial compression $q / p^{\prime}=M=6 \sin \varphi_{\mathrm{c}} /\left(3-\sin \varphi_{\mathrm{c}}\right)$ and $e$ equals the critical void ratio $e_{\mathrm{c}}$.

In Fig. 1(a), some directions of proportional stress paths are shown in the $p^{\prime}-q$ plot. Assuming that soil cannot resist tensile stresses, the admissible stress states are limited by the two lines $\sigma_{1}^{\prime}=0$ and $\sigma_{3}^{\prime}=0$ in Fig. 1(a). Applying proportional strain paths - that is, constant stretchings $\boldsymbol{D}=$ const, proportional stress paths are reached. Proportional stress paths are stress paths in which the ratio of the principal stresses remains constant: $\sigma_{1}^{\prime} / \sigma_{2}^{\prime}=$ const, $\sigma_{2}^{\prime} / \sigma_{3}^{\prime}=$ const, $\sigma_{1}^{\prime} / \sigma_{3}^{\prime}=$ const and thus $q / p^{\prime}=$ const (Goldscheider, 1976; Topolnicki et al., 1990; Chu \& Lo, 1994). It is common to normalise stresses by the so-called Hvorslev's equivalent consolidation pressure $p_{\mathrm{e}}^{\prime *}$

$$
p_{\mathrm{e}}^{\prime *}=\exp \left(\frac{N-\ln (1+e)}{\lambda^{*}}\right)
$$

$p_{\mathrm{e}}^{\prime *}$ is the value of mean stress on the NCL which refers to the current specific volume $(1+e)$ (see Fig. 1(b)). As the isotropic NCL, also other normal compression lines are generally accepted to be parallel with the NCL (Wood, 1990; Mašín, 2012a). For a specific proportional path, $p^{\prime} / p_{\mathrm{e}}^{\prime *}$ is therefore constant and independent of the current void ratio $e$ (see Fig. 1(c)). The same applies for $q / p_{\mathrm{e}}^{\prime *}$. Figure 1(c) shows the ASBS of barodesy for Kaolin clay.

\section{STATE BOUNDARIES IN BARODESY}

Barodesy and hypoplasticity are material models which can both be written as a tensorial equation of the type $\stackrel{\circ}{\boldsymbol{T}}=$ $\boldsymbol{h}(\boldsymbol{T}, \boldsymbol{D}, e)$. Hypoplasticity was developed on the basis of a representation theorem for tensor-valued functions of two tensor-valued arguments. The derivation of barodesy is based on rules by Goldscheider (1976) on asymptotic soil behaviour, compare Kolymbas \& Medicus (2016). The basic structure of barodesy (Kolymbas, 2009) reads

$$
\stackrel{\circ}{\boldsymbol{T}}=c_{3}\|\boldsymbol{T}\|\left(f \boldsymbol{R}^{0}+g \boldsymbol{T}^{0}\right)\|\boldsymbol{D}\|
$$

$\boldsymbol{R}^{0}$ gives the direction of a proportional stress path, $f$ and $g$ are scalar quantities to consider barotropy and pyknotropy. Further details of the mathematical formulation of barodesy are given in Kolymbas (2009, 2012a); Medicus et al. (2012); Kolymbas (2015); Medicus et al. (2016); Kolymbas \& Medicus (2016); Medicus (2015) and Medicus \& Fellin (2017).

The ASBS is obtained by constant stretchings $\boldsymbol{D}$. At asymptotic states the direction of the stress rate coincides with the direction of the actual stress - that is, $\stackrel{\boldsymbol{T}}{=}=a \boldsymbol{T}$ with $a \neq 0$. Critical states are a special form of asymptotic states obtained with isochoric deformation. Critical states are characterised through a vanishing stress rate $\stackrel{\circ}{\boldsymbol{T}}=\mathbf{0}$.

As at critical states, at peak states the stress rate vanishes $(\stackrel{\circ}{\boldsymbol{T}}=\mathbf{0})$. In a drained triaxial test, peak states are obtained through a stress path in a fixed direction. Thus, different

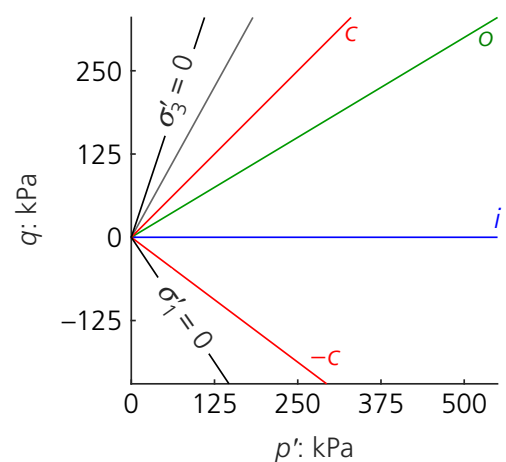

(a)

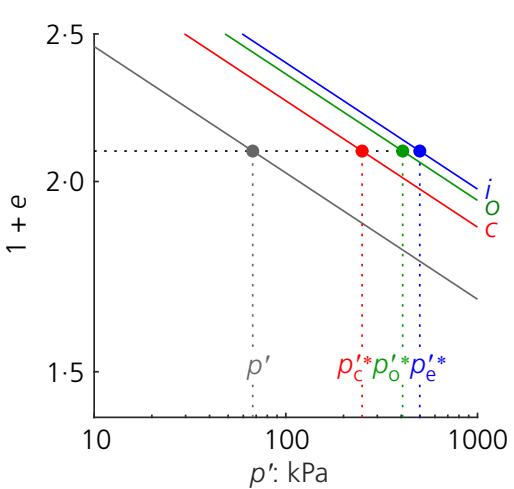

(b)

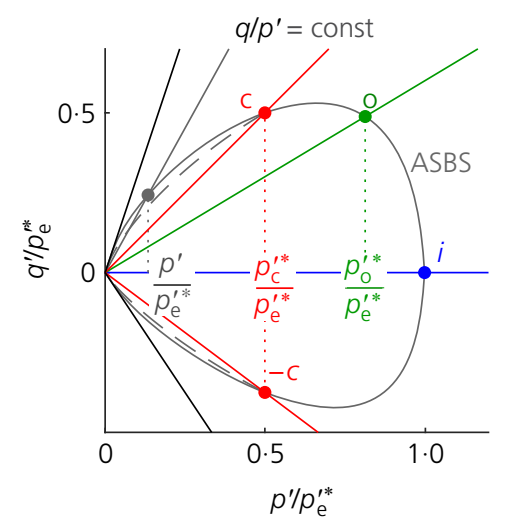

(c)

Fig. 1. Description of state boundaries: $i$ refers to isotropic compression, $c$ is isochoric triaxial compression, $-c$ is isochoric triaxial extension and $o$ is oedometric compression. Kaolin clay is simulated. (a) Proportional stress paths in the $p^{\prime}-q$ plot. (b) Asymptotic states in the $\ln p^{\prime}-\ln (1+e)$ plot; $p_{\mathrm{e}}^{\prime *}$ is the Hvorslev's equivalent pressure and $p_{\mathrm{c}}^{\prime *}$ is the critical pressure, which refers to the current specific volume $(1+e)$. (c) From figures (a) and (b) follows the shape of the ASBS. The dashed line is the normalised peak strength envelope of barodesy 
to proportional paths $\boldsymbol{D}$ is not constant in a drained triaxial test.

\section{ASBS in barodesy}

At asymptotic states the direction of a proportional stress path $\boldsymbol{R}^{0}$ equals the direction of the actual stress $\boldsymbol{T}^{0}$ and, hence, equation (2) yields

$$
\stackrel{\circ}{\boldsymbol{T}}=c_{3}\|\boldsymbol{T}\|(f+g) \boldsymbol{T}^{0}\|\boldsymbol{D}\|
$$

With $\boldsymbol{T}=\|\boldsymbol{T}\| \boldsymbol{T}^{0}$, follows

$$
\stackrel{\circ}{\boldsymbol{T}}=c_{3} \boldsymbol{T}(f+g)\|\boldsymbol{D}\|
$$

Equation (4) is valid for proportional paths. For proportional compression paths $\left(\operatorname{tr} \boldsymbol{D}^{0}<0\right)$ the directions of $\dot{\boldsymbol{T}}$ and $\boldsymbol{T}$ coincide. For dilatant proportional strain paths $\left(\operatorname{tr} \boldsymbol{D}^{0}>0\right.$ ), the directions of $\stackrel{\circ}{\boldsymbol{T}}$ and $\boldsymbol{T}$ are opposite. With $\dot{p}^{\prime}=-1 / 3 \operatorname{tr} \stackrel{\circ}{\boldsymbol{T}}$ from equation (4), follows

$$
\dot{p}^{\prime}=c_{3} p^{\prime}(f+g)\|\boldsymbol{D}\|
$$

With $\quad \operatorname{tr} \boldsymbol{D}=\dot{e} /(1+e) \quad$ and $\quad \operatorname{tr} \boldsymbol{D}=\operatorname{tr} \boldsymbol{D}^{0}\|\boldsymbol{D}\| \quad$ this expression becomes

$$
\frac{\dot{p}^{\prime}}{p^{\prime}}=\frac{c_{3}(f+g)}{\operatorname{tr} D^{0}} \frac{\dot{e}}{1+e}
$$

In barodesy for clay according to Medicus \& Fellin (2017), the scalar quantities in $f+g$ are chosen so that all NCLs in the $\ln p^{\prime}-\ln (1+e)$ plot are parallel to the isotropic NCL. They all can be expressed by

$$
\frac{\dot{p}^{\prime}}{p^{\prime}}=\frac{1}{\lambda^{*}} \frac{\dot{e}}{1+e}
$$

Comparing equations (6) and (7) gives

$$
\frac{c_{3}}{\operatorname{tr} \boldsymbol{D}^{0}}(f+g)=1 / \lambda^{*}
$$

The scalar quantity $f+g$ according to Medicus $\&$ Fellin (2017) is

$$
f+g=\left(\frac{1+e}{1+e_{\mathrm{c}}}\right)^{c_{5}}-1+\beta \operatorname{tr} \boldsymbol{D}^{0}
$$

From equations (8) and (9) follows

$$
\frac{1+e}{1+e_{\mathrm{c}}}=\left(\frac{\operatorname{tr} \boldsymbol{D}^{0}}{c_{3} \lambda^{*}}+1-\beta \operatorname{tr} \boldsymbol{D}^{0}\right)^{1 / c_{5}}
$$

If $(1+e) /\left(1+e_{\mathrm{c}}\right)$ is constant for a proportional path, $p^{\prime} / p_{\mathrm{e}}^{\prime *}$ is constant as well according to Fig. 1(b). The following relation applies (Medicus, 2015)

$$
\frac{1+e}{1+e_{\mathrm{c}}}=\left(2 \frac{p^{\prime}}{p_{\mathrm{e}}^{\prime *}}\right)^{\lambda^{*}}
$$

With equation (11), equation (10) is expressed by

$$
\frac{p^{\prime}}{p_{\mathrm{e}}^{\prime *}}=\frac{1}{2}\left(\frac{-\operatorname{tr} \boldsymbol{D}^{0} / \lambda^{*}+c_{3}-c_{3} \operatorname{tr} \boldsymbol{D}^{0} \beta}{c_{3}}\right)^{1 / \lambda^{*} c_{5}}
$$

Equation (12) introduces $p^{\prime} / p_{\mathrm{e}}^{\prime *}$ of the ASBS of barodesy for clay with $c_{3}$ and $c_{5}$ as constants and $\beta$ as a function of $\operatorname{tr} \boldsymbol{D}^{0}$ (see Table 1).
Table 1. Determination of $c_{i}$ from $\varphi_{c}, \lambda^{*}, \kappa^{*}$ and scalar quantities $\beta$ and $\Lambda$ as functions of $\operatorname{tr} D^{0}$

$$
\begin{aligned}
& c_{1}=\frac{2 \sqrt{2 / 3} \ln K_{\mathrm{c}}-2 \ln K_{0}}{1-\left(2 /(-1-\sqrt{2})^{2}\right)} \\
& c_{2}=\ln K_{0}+\frac{c_{1}^{2}}{(-1-\sqrt{2})^{2}} \\
& c_{3}=\frac{-\sqrt{3} / \lambda^{*}+\sqrt{3} / \kappa^{*}}{2^{c_{5} \lambda^{*}}+(1 / 500)^{c_{5} \lambda^{*}}-2} \\
& c_{5}=\frac{1}{K_{\mathrm{c}}} \\
& K_{\mathrm{c}}=\frac{1-\sin \varphi_{\mathrm{c}}}{1+\sin \varphi_{\mathrm{c}}} \\
& K_{0}=\frac{9-7 \sin \varphi_{\mathrm{c}}}{9+5 \sin \varphi_{\mathrm{c}}} \\
& \beta=-\frac{1}{c_{3} \Lambda}+\frac{1}{\sqrt{3}} 2^{c_{5} \lambda^{*}}-\frac{1}{\sqrt{3}} \\
& \Lambda=-\frac{\lambda^{*}-\kappa^{*}}{2 \sqrt{3}} \operatorname{tr} D^{0}+\frac{\lambda^{*}+\kappa^{*}}{2}
\end{aligned}
$$

Source: Medicus \& Fellin (2017).

At asymptotic states $q / p_{\mathrm{e}}^{\prime *}$ is constant as well with $p^{\prime} / p_{\mathrm{e}}^{\prime *}=$ const and with $q / p^{\prime}=$ const

$$
\frac{q}{p_{\mathrm{e}}^{\prime *}}=\frac{q}{p^{\prime}} \frac{p^{\prime}}{p_{\mathrm{e}}^{\prime *}}
$$

with $p^{\prime} / p_{\mathrm{e}}^{\prime *}$ from equation (12). The stress ratio $q / p^{\prime}$ in dependence of the stress ratio $K=\sigma_{3}^{\prime} / \sigma_{1}^{\prime}$ is

$$
\frac{q}{p^{\prime}}=\frac{3-3 K}{1+2 K}
$$

$K$ can be formulated as a function of $\operatorname{tr} \boldsymbol{D}^{0}$ and is chosen according to Medicus \& Fellin (2017)

$$
K=1-\frac{1}{1+c_{1}\left(m-c_{2}\right)^{2}} \text { with } m=\frac{-3 \operatorname{tr} \boldsymbol{D}^{0}}{\sqrt{6-2 \operatorname{tr} \boldsymbol{D}^{02}}}
$$

In equation (15) $c_{1}$ and $c_{2}$ are material constants which are determined by $\varphi_{\mathrm{c}}$ (see Table 1 ).

The ASBS in barodesy follows with $p^{\prime} / p_{\mathrm{e}}^{\prime *}$ (equation (12)) and $q / p^{\prime}$ (equations (14) and (15)) with the parameters and functions according to Table 1 . For example, for $\operatorname{tr} \boldsymbol{D}^{0}=$ 0 follows $q / p^{\prime}=M$ in equation (14) and the critical state line (CSL) with $p^{\prime} / p_{\mathrm{e}}^{\prime *}=1 / 2$ in equation (10). For $\operatorname{tr} D^{0}=-\sqrt{3}$ follows the hydrostatic axis $\left(q / p^{\prime}=0\right.$ in equation (14)) and the isotropic NCL with $p^{\prime} / p_{\mathrm{e}}^{\prime *}=1$ in equation (10). For oedometric conditions - that is, $\operatorname{tr} \boldsymbol{D}^{0}=$ -1 , follows Jáky's prediction for $\sigma_{3}^{\prime} / \sigma_{1}^{\prime}=1-\sin \varphi_{\mathrm{c}}$ and the oedometric NCL with $1 / 2<p^{\prime} / p_{\mathrm{e}}^{\prime *}<1$. Figures 1 (c) and 2 show the ASBS according to Kaolin clay. The full sets of parameters of different clay types to calibrate barodesy and hypoplasticity are summarised in Table 2.

A three-dimensional (3D) formulation of the locus of asymptotic stress states is

$$
\begin{gathered}
\left(\ln \frac{-\sigma_{1}^{\prime}}{\sqrt[3]{-\sigma_{1}^{\prime} \sigma_{2}^{\prime} \sigma_{3}^{\prime}}}\right)^{2}+\left(\ln \frac{-\sigma_{2}^{\prime}}{\sqrt[3]{-\sigma_{1}^{\prime} \sigma_{2}^{\prime} \sigma^{\prime}}}\right)^{2} \\
+\left(\ln \frac{-\sigma_{3}^{\prime}}{\sqrt[3]{-\sigma_{1}^{\prime} \sigma_{2}^{\prime} \sigma^{\prime}}}\right)^{2}=\frac{2}{3}(\ln K)^{2}
\end{gathered}
$$

For $\operatorname{tr} \boldsymbol{D}^{0}=0$ equation (16) yields the critical state locus according to Kolymbas (2012b) with $K=$ $\left(1-\sin \varphi_{\mathrm{c}}\right) /\left(1+\sin \varphi_{\mathrm{c}}\right)$. 3D representations of the ASBS of Kaolin clay are given in Fig. 2. 


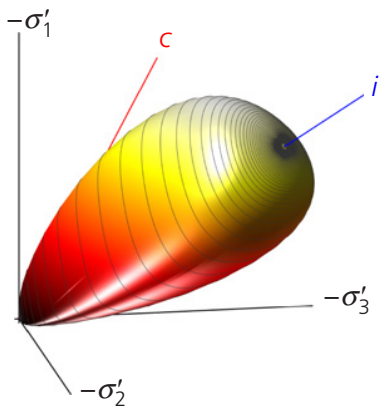

(a)

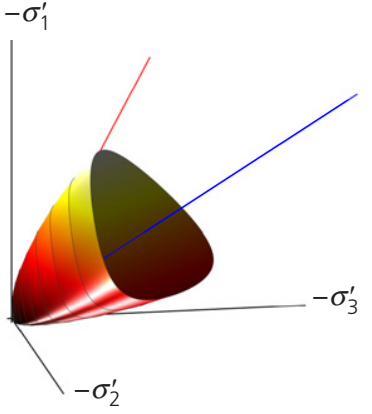

(b)

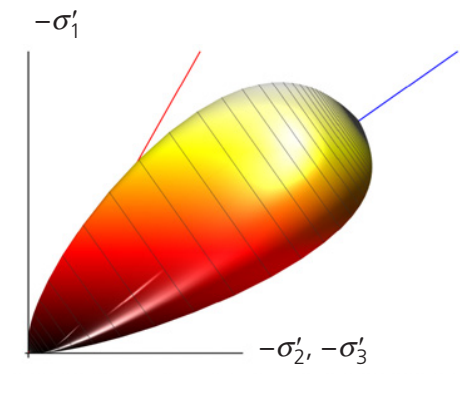

(c)

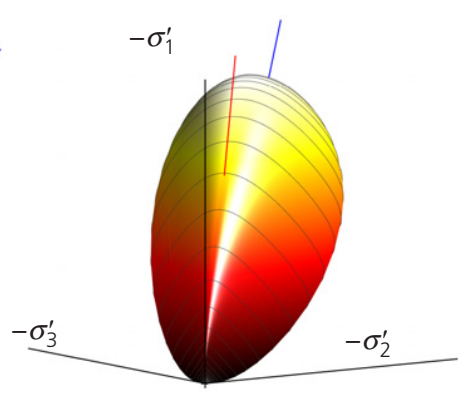

(d)

Fig. 2. Different views of the ASBS for $e=$ const of Kaolin clay, simulated with barodesy. The blue line is the hydrostatic axis $(i)$, the red line is the CSL for axisymmetric triaxial compression (c)

Table 2. Critical state soil mechanics parameters of the investigated clays

\begin{tabular}{l|c|c|c|c|c}
\hline $\begin{array}{l}\text { Barodesy and } \\
\text { hypoplasticity }\end{array}$ & $M$ & $N$ & $\lambda^{*}$ & $\kappa^{*}$ & $v$ \\
\hline Kaolin clay & 1.00 & 1.255 & $0 \cdot 083$ & 0.017 & 0.33 \\
Oxford clay & 1.00 & 1.150 & $0 \cdot 110$ & 0.010 & 0.33 \\
Gault clay & 0.94 & 1.095 & $0 \cdot 095$ & 0.011 & 0.33 \\
Kimmeridge clay & 0.84 & 1.165 & $0 \cdot 110$ & 0.0135 & 0.33 \\
Weald clay & 0.94 & 0.8 & 0.059 & 0.014 & 0.3 \\
\hline Atkinson (2007) & $M$ & $v_{\Gamma}$ & $\lambda$ & $\kappa$ & $b$ \\
\hline Kaolin clay & 1.00 & $3 \cdot 14$ & $0 \cdot 190$ & 0.050 & 0.63 \\
Oxford clay & 1.00 & 2.65 & $0 \cdot 191$ & 0.027 & 0.48 \\
Gault clay & 0.94 & 2.58 & $0 \cdot 168$ & 0.032 & 0.47 \\
Kimmeridge clay & 0.84 & 2.68 & 0.192 & 0.032 & 0.64 \\
\hline
\end{tabular}

The mentioned parameters are sufficient to calibrate the models. Weald clay parameters are from Mašín (2013). The parameter $v$ is needed for the calibration of clay hypoplasticity.

\section{Peak states in barodesy}

Peak states of drained triaxial tests are a special form of state boundaries. For a drained triaxial test - that is, $\dot{\sigma}_{3}^{\prime}=0$, the peak friction angle for highly overconsolidated soil exceeds the critical friction angle and is dependent on dilatancy at peak state. In barodesy, critical and peak states are states with $\boldsymbol{R}^{0}=\boldsymbol{T}^{0}$. They are characterised through $\stackrel{\circ}{\boldsymbol{T}}=\mathbf{0}$. According to equation (2) peak states are thus characterised through $f+g=0$ (see Kolymbas, 2015). With equation (9) follows from $f+g=0$

$$
\frac{1+e}{1+e_{\mathrm{c}}}=\left(1-\beta \operatorname{tr} \boldsymbol{D}^{0}\right)^{1 / c_{5}}
$$

and thus

$$
\frac{p^{\prime}}{p_{\mathrm{e}}^{\prime *}}=\frac{1}{2}\left(1-\beta \operatorname{tr} \boldsymbol{D}^{0}\right)^{1 / \lambda^{*} c_{5}}
$$

With equation (19), $p^{\prime} / p_{\mathrm{e}}^{\prime *}$ of the peak envelope of barodesy is introduced and together with equation (14) the peak envelopes (dashed lines) shown in Figs 1(c) and 3(b) are obtained.

Figure 3(a) shows simulations of drained triaxial tests with barodesy. Figure 3(b) shows the ASBS and the peak state envelope according to barodesy. The peak states from (a) are marked in (b). A peak state in a drained triaxial test corresponds to the maximum value of $q / p^{\prime}$. Figure 3(c) shows the results of hypoplasticity (Mašín, 2013). In barodesy and hypoplasticity, the ASBSs do not include peak states, but the peak envelopes lie inside the ASBSs. For the representation of peak states it is sufficient to display the dry side of critical state and normalise stresses $p^{\prime}$ and $q$ by $p_{\mathrm{c}}^{\prime *}$ according to Fig. 1(b) (see Fig. 4).

\section{COMPARISON WITH EXPERIMENTAL DATA}

To compare the experimental data according to Atkinson (2007) with hypoplasticity and barodesy, their parameters have to be calibrated: Atkinson (2007) provides the parameters $v_{\Gamma}, \lambda$ and $\kappa$ according to Table 2, to describe the compression and critical state behaviour of the investigated clays. $v_{\Gamma}, \lambda$ and $\kappa$ are defined in the $\ln p^{\prime}-(1+e)$ plot according to Fig. 5(a). The mean stress on the CSL is $p_{\mathrm{c}}^{\prime}$. Barodesy and hypoplasticity include the parameters $N, \lambda^{*}$ and $\kappa^{*}$, which are defined in the $\ln p^{\prime}-\ln (1+e)$ plot (Butterfield, 1979; Mašín, 2005). The mean stress on the CSL is $p_{\mathrm{c}}^{\prime *}$. The parameters $\lambda$ and $\lambda^{*}\left(\kappa\right.$ and $\kappa^{*}, v_{\Gamma}$ and $N$, respectively) cannot be directly converted into each other. However, they can be easily adjusted for a relevant stress range, as shown in Figs 5(a) and 5(b). The different parameters resulting from the different approaches are summarised in Table 2. They are used for the simulations in this paper.

The peak data of Atkinson (2007) are displayed in Figs 5(c) and 7. The power law according to Atkinson (2007) to fit peak states is

$$
\frac{q}{p_{\mathrm{c}}^{\prime}}=M\left(\frac{p^{\prime}}{p_{\mathrm{c}}^{\prime}}\right)^{b}
$$

with the parameters $M$ and $b$ from Table 2. To exactly compare the power law with barodesy and hypoplasticity it is modified according to Shi et al. (2017)

$$
\frac{q}{p_{\mathrm{c}}^{\prime *}}=M\left(\frac{p^{\prime}}{p_{\mathrm{c}}^{\prime *}}\right)^{b}
$$

As shown in Fig. 5(b), $p_{\mathrm{c}}^{\prime *}$ and $p_{\mathrm{c}}^{\prime}$ are very similar for the calibrated stress range. There is good agreement between the models predictions, the relation according to equation (20) and the experimental data.

According to equations (14) and (17), the parameters $M$ ( $\varphi_{\mathrm{c}}$ respectively), $\lambda^{*}$ and $\kappa^{*}$ influence the shape of the peak strength envelope in barodesy. With the standard calibration procedure of barodesy, the overall accordance to describe the peak states of drained triaxial tests for the investigated clays is satisfactory. For hypoplasticity (Mašín, 2013), the parameters $M$ and $a$ are sufficient to define the ASBS in normalised stress space. The peak strength in hypoplasticity is - besides $M$ and $a$-influenced by the parameter $v$ : the higher $v$ is, the lower the peaks are and the lower the initial 

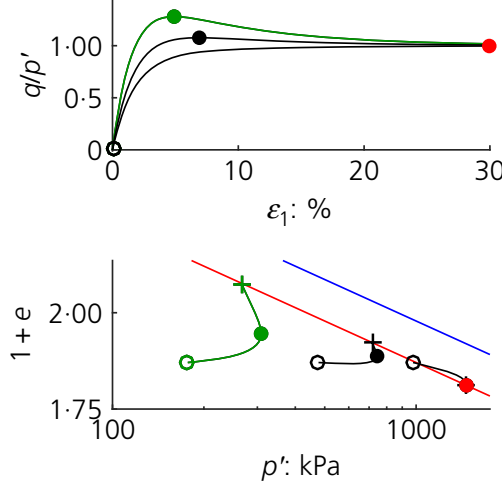

(a)

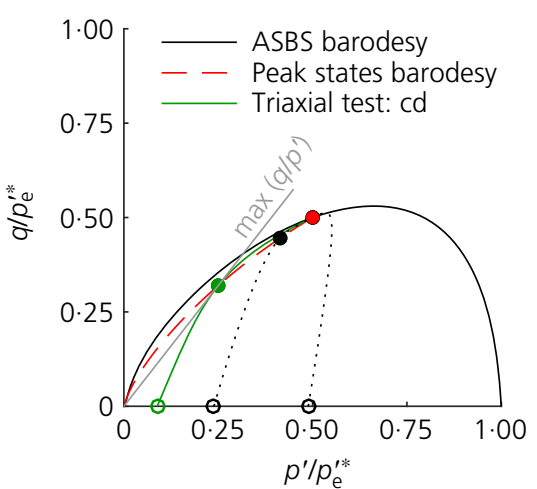

(b)

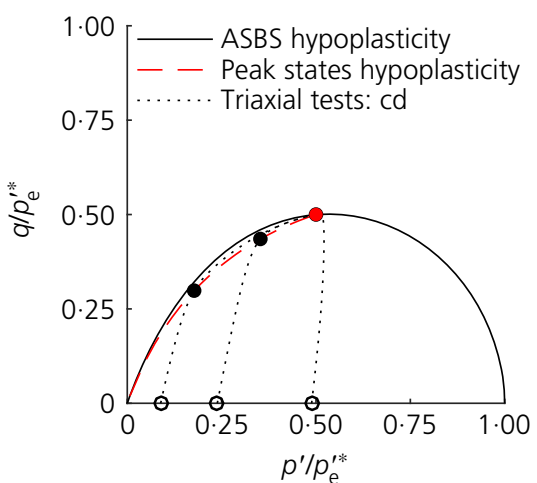

(c)

Fig. 3. ASBS and peak states in barodesy and hypoplasticity of Kaolin clay: (a) simulations of drained triaxial tests (cd) with barodesy. (b) ASBS and peak state envelope according to barodesy, a peak state in a drained triaxial test corresponds to the maximum value of $q / p^{\prime}$. (c) Results of clay hypoplasticity by Mašín (2013). The paths of drained triaxial tests are added in (b) and (c). Initial states are marked with $\circ$, peak states are marked with $\bullet$, critical states are marked with $\bullet$

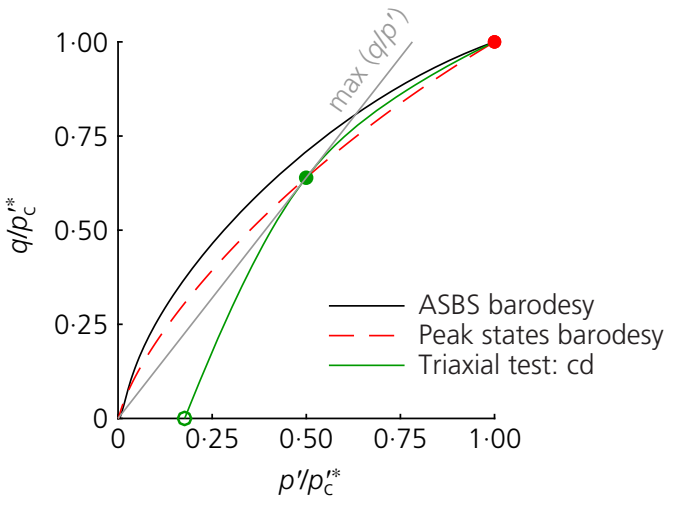

Fig. 4. A detail of Fig. 3(b). For the representation of peak states it is sufficient to display the dry side of critical state and normalise stresses $p^{\prime}$ and $q$ with $p_{c}^{\prime *}$ according to Fig. 1(b). The initial state of the drained triaxial test is marked with $\circ$, the peak (i.e. the maximum value of $q / p^{\prime}$ ) is marked with $\bullet$ and critical state is marked with . stiffness is. The parameter $v$ is proposed to be calibrated by parametric study with deviatoric stress-deviatoric strain curves of a shear test (Mašín, 2005, 2013). Due to the lack of stress-strain curves of the investigated clays, $v$ cannot be calibrated as proposed and is set to 0.33 for all clays.

In the simulations in Fig. 5(c) the parameter $a$ is chosen to $a=-0 \cdot 1$ to match peak states of Kaolin. The simulations with hypoplasticity are shown in Fig. 6, the parameter $a$ is varied in order to show its sensitivity relating to peak strength. In the simulations in Figs 3(c) and 7, the default value of $a=0.3$ is kept. Due to a scatter of the peak strength it is proposed to use the default value, unless one has a reliable data basis consisting of several peak states.

Asymptotic states for undrained triaxial compression are critical states with $e=e_{\mathrm{c}}\left(p_{\mathrm{c}}^{\prime *} / p_{\mathrm{e}}^{\prime *}=0.5\right)$ and $q / p^{\prime}=M$ (see Fig. 8). Undrained shear strength $c_{\mathrm{u}}$ at critical states is related to the void ratio - for example, Wood (1990) and Atkinson (2007). The predictions of barodesy and hypoplasticity for $c_{\mathrm{u}}$ under undrained triaxial compression are in accordance with critical state soil mechanics with

$$
c_{\mathrm{u}}=M / 2 p_{\mathrm{c}}^{\prime *}=M / 4 p_{\mathrm{e}}^{* *}=M / 4 \exp \left(\frac{N-\ln (1+e)}{\lambda^{*}}\right)
$$

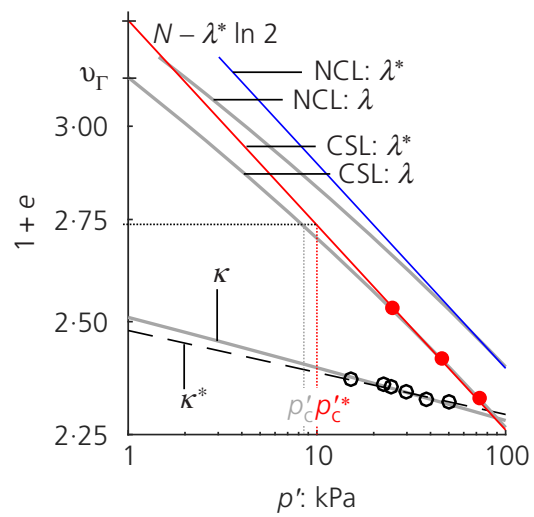

(a)

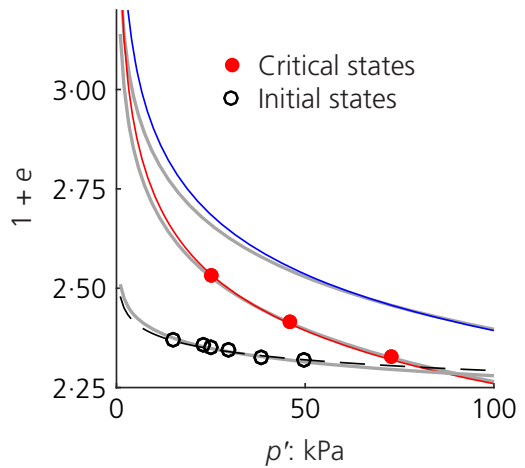

(b)

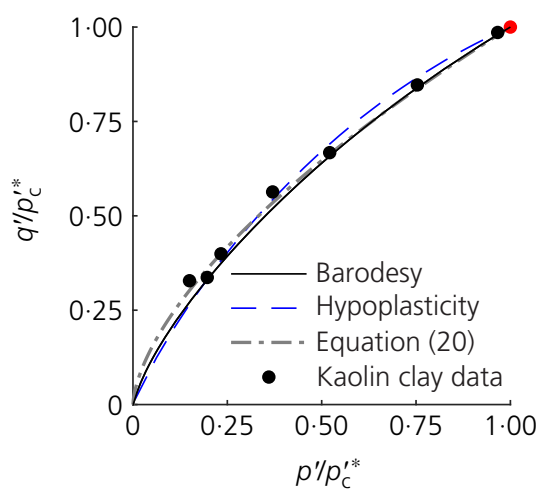

(c)

Fig. 5. Comparison of normal compression, critical state and peak state relations for clay with Kaolin clay data $(\bullet, \circ)$ by Atkinson (2007): (a) as for the NCL, formulations for the CSL defined in the $\ln p^{\prime}-(1+e)$ and $\ln p^{\prime}-\ln (1+e)$ plots can be found. $v_{\Gamma}$ is $1+e_{\mathrm{c}}$ at $p=1 \mathrm{kPa}$, the CSL is a line in the $\ln p^{\prime}-(1+e)$ plot. $N-\lambda^{*} \ln 2$ is $\ln \left(1+e_{\mathrm{c}}\right)$ at $p=1 \mathrm{kPa}$, the CSL is a line in the $\ln p^{\prime}-\ln (1+e)$ plot. $p_{\mathrm{c}}^{\prime}$ and $p_{\mathrm{c}}^{\prime *}$ are marked for an arbitrary $(1+e)$. (b) Both approaches describe well the critical state data in the $p^{\prime}-e$ plot. (c) Peak states data of drained triaxial tests of Kaolin clay $(\bullet)$ are compared with the relation proposed by Atkinson (2007) adopted by Shi et al. (2017) (equation (20)), hypoplasticity and barodesy 
In barodesy, the maximum mobilised friction angle under undrained triaxial compression does not exceed the critical friction angle. This shortcoming for highly overconsolidated soil is discussed by Medicus \& Fellin (2017). Barodesy therefore underestimates the maximum mobilised friction angle of the highly overconsolidated Weald clay sample in Fig. 8. In hypoplasticity, the maximum mobilised friction angle of the highly overconsolidated sample in Fig. 8 is overestimated with the default value of $a=0 \cdot 3$. A reduction of $a$ improves the predictions of the maximum mobilised friction angles for the undrained response of the highly overconsolidated sample in Fig. 8.

\section{INVESTIGATIONS IN THE DEVIATORIC PLANE}

In Figs 2(b) and 9(a) cross-sections of the ASBS with a deviatoric plane are shown for critical states. Critical states include asymptotic states (obtained with $\operatorname{tr} \boldsymbol{D}^{0}=0$ ) and peak states of initially normally to slightly overconsolidated drained triaxial tests. Critical states are characterised through zero dilatancy at failure. Fellin \& Ostermann (2013) have shown that the critical state locus of barodesy (Fig. 9(a)) practically coincides with the locus according to Matsuoka-Nakai.

A realistic shape of the failure surface is necessary but not a sufficient condition for realistic predictions under isochoric plane strain. The directions of stress or strain paths in the deviatoric plane are given by the Lode angles $\alpha_{\sigma}$

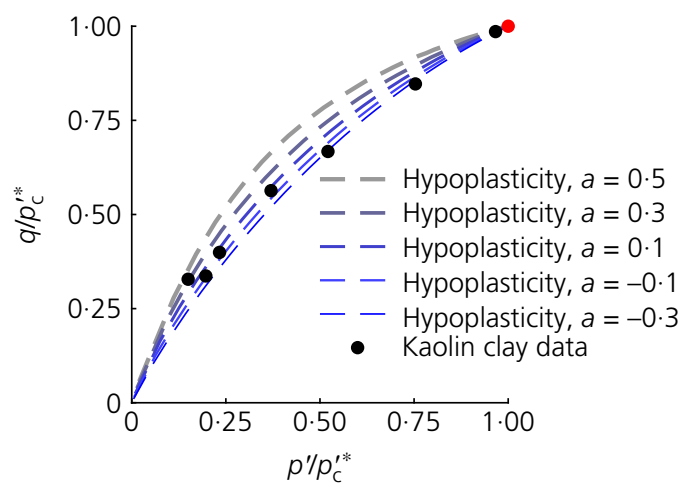

Fig. 6. Parameter a of hypoplasticity is varied in order to show its sensitivity relating to peak strength. The larger $a$ is, the higher is the peak strength. Peak data of Kaolin clay $(\bullet)$ by Atkinson (2007) (equation (21)) and $\alpha_{\dot{\varepsilon}}$ (equation (22)).

$$
\begin{aligned}
& \alpha_{\sigma}=\frac{1}{3} \arcsin \frac{-3 \sqrt{6} \operatorname{det} \boldsymbol{T}^{*}}{\left|\boldsymbol{T}^{*}\right|^{3}} \text { with } \boldsymbol{T}^{*}=\boldsymbol{T}-\frac{\operatorname{tr} \boldsymbol{T}}{3} \mathbf{1} \\
& \alpha_{\dot{\varepsilon}}=\frac{1}{3} \arcsin \frac{-3 \sqrt{6} \operatorname{det} \boldsymbol{D}^{*}}{\left|\boldsymbol{D}^{*}\right|^{3}} \text { with } \boldsymbol{D}^{*}=\boldsymbol{D}-\frac{\operatorname{tr} \boldsymbol{D}}{3} \mathbf{1}
\end{aligned}
$$

Triaxial compression corresponds to a Lode angle $\alpha_{\dot{\varepsilon}}=\alpha_{\sigma}$ of $30^{\circ}$, triaxial extension to $\alpha_{\dot{\varepsilon}}=\alpha_{\sigma}=-30^{\circ}$. If the Lode angles $\alpha_{\sigma}$ and $\alpha_{\dot{\varepsilon}}$ coincide for rectilinear deformations, then the so-called alignment between deviatoric stress and deviatoric stretching exists, compare Schaeffer (1987); Barker et al. (2017) and Rauter et al. (2020). For $-30^{\circ}<$ $\alpha_{\sigma}<30^{\circ}, \alpha_{\dot{\varepsilon}}$ differs from $\alpha_{\sigma}$ in barodesy (see Fig. 9(b)) and Medicus et al. (2016). Investigations by Goldscheider (1976) with true triaxial tests on sand showed that $\alpha_{\dot{\varepsilon}}$ differs from $\alpha_{\sigma}$ for $-30^{\circ}<\alpha_{\sigma}<30^{\circ}$. In clay hypoplasticity $\alpha_{\sigma}$ coincides with $\alpha_{\dot{\varepsilon}}$ according to Fig. 9(b). For isochoric strain paths, a Lode angle $\alpha_{\dot{\varepsilon}}=0^{\circ}$ corresponds to plane strain failure (see Fig. 9(a)). The corresponding Lode angle $\alpha_{\sigma}$ is dependent of the stress-dilatancy relation included in the material model. For the simulations in Figs 9(a) and 9(b) that is, for $\varphi_{\mathrm{c}}=25.4^{\circ}$, follows from the stress-dilatancy

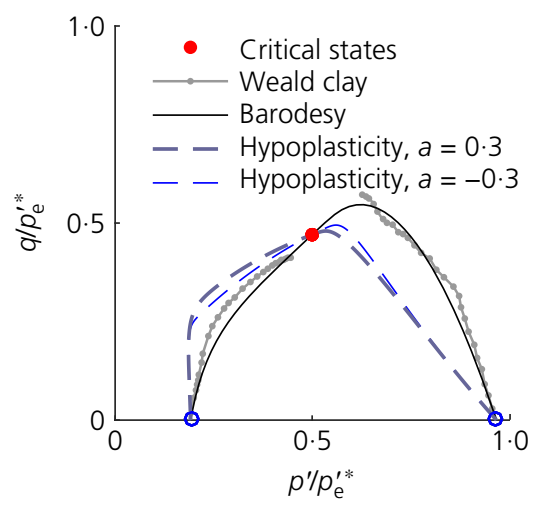

Fig. 8. Undrained triaxial compression of Weald clay (according to Mašín (2013), data by Parry, 1960) and numerical simulation with barodesy and hypoplasticity. The initial states of the normally consolidated and overconsolidated samples are $e_{0}=$ 0.622 and $e_{0}=0.572$. The start points are denoted by a circle (o), critical states (asymptotic states for undrained compression) are marked with (०)

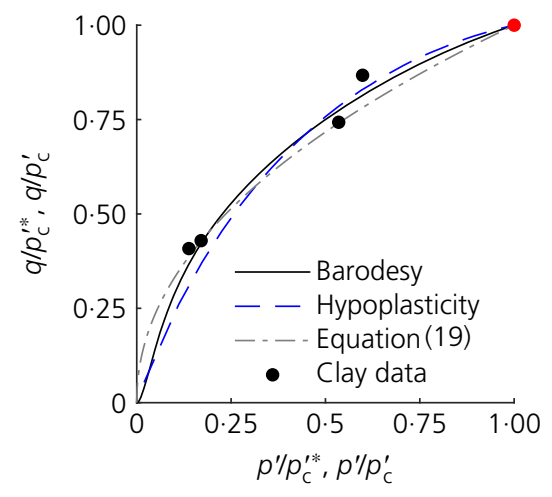

(a)

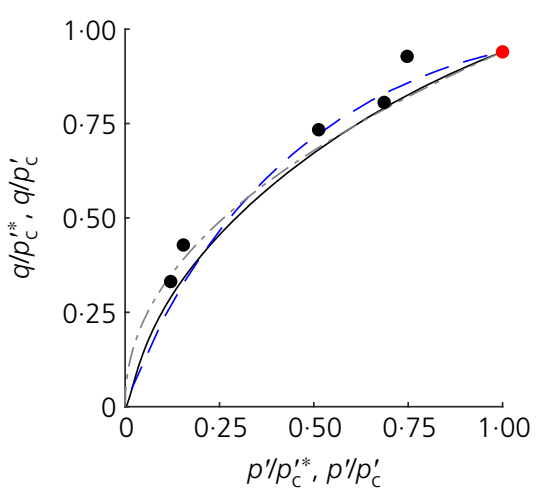

(b)

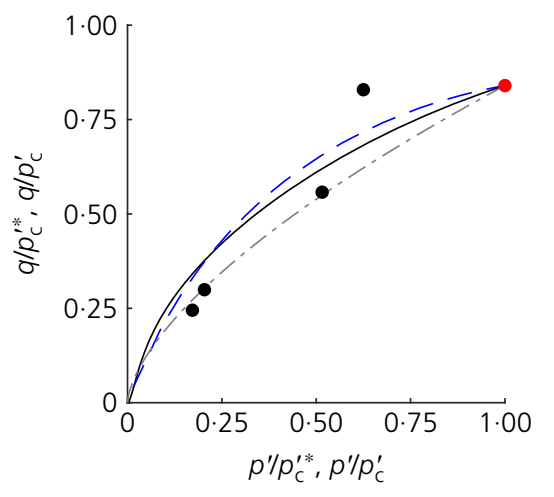

(c)

Fig. 7. Peak states of drained triaxial tests of (a) Oxford, (b) Gault, (c) Kimmeridge clay. Data (•) from Atkinson (2007) are compared with equation (20), hypoplasticity and barodesy. Note that the clay data (except for Kaolin clay in Fig. 5(c)) are only given in the normalised stress space $p / p_{c}^{\prime}-q / p_{c}^{\prime}$ by Atkinson (2007). Hypoplasticity, barodesy and equation (20) refer to a $p / p_{c}^{\prime *}-q / p_{c}^{\prime *}$ formulation. As shown in Figs $5(\mathrm{a})$ and $5(\mathrm{~b}), p_{\mathrm{c}}^{\prime *}$ and $p_{\mathrm{c}}^{\prime}$ are very similar to the calibrated stress range. A comparison is therefore admissible 


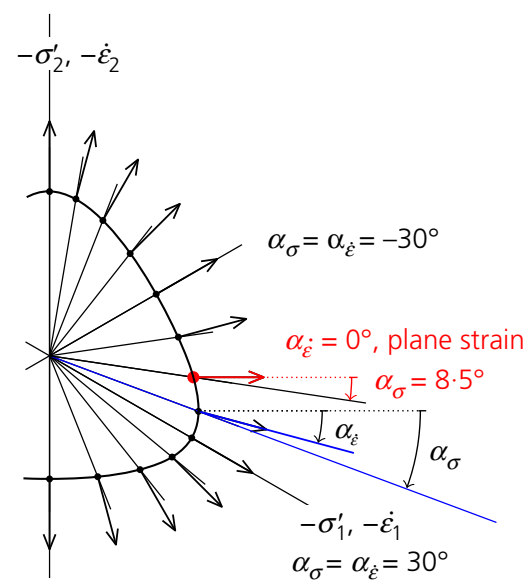

(a)

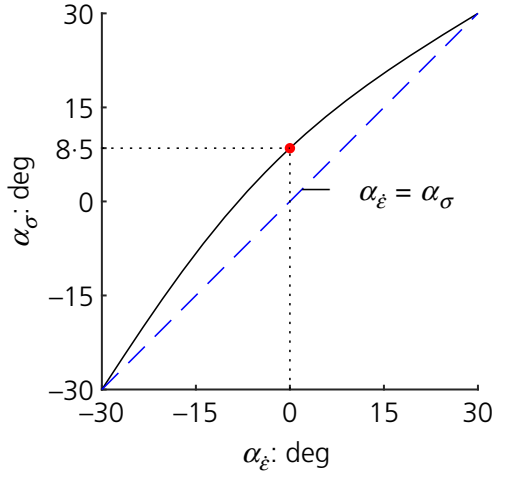

(b)

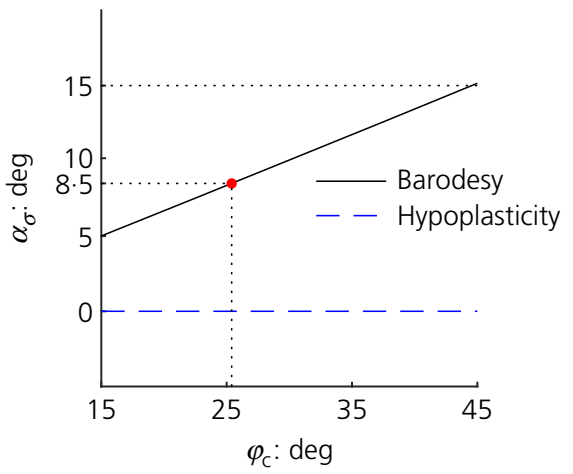

(c)

Fig. 9. Critical states in the deviatoric plane: (a) the full line is the cross-section of the critical stress surface of barodesy for Kaolin clay (i.e. $M=1$ and thus $\varphi_{\mathrm{c}}=25.4^{\circ}$ ) with the deviatoric plane $\operatorname{tr} \boldsymbol{T}=-300 \mathrm{kPa}$, the arrows denote the deviatoric directions of proportional strain paths. For isochoric ( $\operatorname{tr} \boldsymbol{D}=0$ ) plane strain compression, it follows $\alpha_{\dot{\varepsilon}}=0^{\circ}$. (b) The deviatoric directions of stress and strain paths are shown for $\varphi_{\mathrm{c}}=25.4^{\circ}$ according to (a). In hypoplasticity $\alpha_{\sigma}=\alpha_{\dot{\varepsilon}}$ for isochoric conditions. (c) Dependence of $\alpha_{\sigma}$ on $\varphi_{\mathrm{c}}$ under plane strain isochoric failure. The higher the critical friction angle of a material is, the higher is the Lode angle for plane strain isochoric failure in barodesy. In hypoplasticity $\alpha_{\sigma}=0^{\circ}$ for plane strain conditions. For $15^{\circ}<\varphi_{\mathrm{c}}<45^{\circ}$, it follows $5^{\circ}<\alpha_{\sigma}<15^{\circ}$. The predictions of barodesy for plane strain failure and $\varphi_{\mathrm{c}}=25 \cdot 4^{\circ}$ is marked (॰) in (a), (b) and (c)

relation in barodesy that $\alpha_{\sigma}=8 \cdot 5^{\circ}$. Stress paths of normally consolidated soil under plane strain failure are reported to lie within $0^{\circ} \leq \alpha_{\sigma} \leq 15^{\circ}$ (Nakai, 2007). Potts \& Zdravković (1999) report that $0.15 \leq\left|\left(\sigma_{2}^{\prime}-\sigma_{3}^{\prime}\right) /\left(\sigma_{1}^{\prime}-\sigma_{3}^{\prime}\right)\right| \leq 0.35$ for biaxial tests on clays, which corresponds to $10^{\circ} \leq \alpha_{\sigma} \leq 22^{\circ}$. Figure 9(c) shows the predictions of barodesy for $\alpha_{\sigma}$ under isochoric plane strain failure for materials with various critical friction angles: the higher the critical friction angle of a material is, the higher is the Lode angle. It is to be presumed that with inhibited lateral expansion $\left(\varepsilon_{2}=0\right)$, lower values of intermediate principal stresses $\left|\sigma_{2}^{\prime}\right|$ develop for materials with higher strength (i.e. a higher critical friction angle). Lower stresses $\left|\sigma_{2}^{\prime}\right|$ (with unchanged $\sigma_{1}^{\prime}$ and $\sigma_{3}^{\prime}$ ) correspond to higher Lode angles $\alpha_{\sigma}$. Note that the simulations correspond to zero dilatancy at failure. For the range of critical friction angles $\left(15^{\circ}<\varphi_{\mathrm{c}}<45^{\circ}\right)$, it follows in barodesy that $5^{\circ} \leq \alpha_{\sigma} \leq 15^{\circ}$ (see Fig. 9(c)) Hypoplasticity follows $\alpha_{\sigma}=0^{\circ}$ for isochoric plane strain failure for any critical friction angle. $\alpha_{\sigma}=0^{\circ}$ corresponds to $\sigma_{2}^{\prime}=\left(\sigma_{1}^{\prime}+\sigma_{3}^{\prime}\right) / 2$. Both models (barodesy and hypoplasticity) predict Lode angles under plane strain conditions that are given in the literature - for example, Nakai (2007).

\section{CONCLUSIONS}

In this paper, the ASBS and peak state envelope according to barodesy for clay are introduced. The surfaces are compared with the ones according to

- clay hypoplasticity with explicitly defined asymptotic states by Mašín (2013)

- a relation proposed by Atkinson (2007), modified by Shi et al. (2017)

- experimental data of different clay types by Atkinson (2007).

It is shown that the ASBS does not include peak states in barodesy and hypoplasticity, which is different to elastoplastic models. The predictions of hypoplasticity and barodesy for the peak states of drained triaxial tests are in accordance with experimental data: the peak strength envelope in the normalised stress space is curved with zero strength at vanishing stress. For isochoric plane strain failure, barodesy and hypoplasticity predict Lode angles in a range, which is experimentally confirmed.

\section{ACKNOWLEDGEMENTS}

This research is funded by the Austrian Science Fund (FWF): P 28934. The author thanks Wolfgang Fellin for the encouragement to write this paper and Manuel Bode, Ivo Herle, Dimitrios Kolymbas and David Mašín for valuable discussion. The author further acknowledges the remarks of the three reviewers, which all further improved the paper.

\section{REFERENCES}

Atkinson, J. (2007). Peak strength of overconsolidated clays. Géotechnique 57, No. 2, 127-135, https://doi.org/10.1680/geot. 2007.57.2.127.

Barker, T., Schaeffer, D. G., Shearer, M. \& Gray, J. (2017) Well-posed continuum equations for granular flow with compressibility and $\mu$ (i)-rheology. Proc., Math., Phys., Engng Sci. 473, No. 2201, https://doi.org/10.1098/rspa.2016.0846.

Barnes, G. E. (2010). Soil mechanics: principles and practice. Palgrave Macmillan, London, UK.

Bergholz, K. \& Herle, I. (2017). Experimentelle Bestimmung der Nichtlinearität von Spannungsgrenzbedingungen im Bereich geringer Spannungen. Geotechnik 40, No. 2, 119-125, https://doi.org/10.1002/gete.201600008 (in German).

Butterfield, R. (1979). A natural compression law for soils (an advance on $e-\log p^{\prime}$ ). Géotechnique 29, No. 4, 469-480, https://doi.org/10.1680/geot.1979.29.4.469.

Chu, J. \& Lo, S. C. R. (1994). Asymptotic behaviour of a granular soil in strain path testing. Géotechnique 44, No. 1, 65-82, https://doi.org/10.1680/geot.1994.44.1.65.

Fellin, W. \& Ostermann, A. (2013). The critical state behaviour of barodesy compared with the Matsuoka-Nakai failure criterion. Int. J. Numer. Anal. Methods Geomech. 37, No. 3, 299-308, https://doi.org/10.1002/nag.1111.

Goldscheider, M. (1976). Grenzbedingung und Fließregel von Sand. Mech. Res. Commun. 3, 463-468 (in German). 
Gudehus, G. (2011). Physical soil mechanics. Berlin, Germany: Springer.

Gudehus, G. \& Mašín, D. (2009). Graphical representation of constitutive equations. Géotechnique 59, No. 2, 147-151, https://doi.org/10.1680/geot.2007.00155.

Kolymbas, D. (2009). Sand as an archetypical natural solid. In Mechanics of natural solids (eds D. Kolymbas and G. Viggiani, pp. 1-26. Berlin, Germany: Springer.

Kolymbas, D. (2012a). Barodesy: a new constitutive frame for soils. Géotech. Lett. 2, No. 2, 17-23, https://doi.org/10.1680/ geolett.12.00004.

Kolymbas, D. (2012b). Barodesy: a new hypoplastic approach. Int. J. Numer. Anal. Methods Geomech. 36, No. 9, 1220-1240, https://doi.org/10.1002/nag.1051.

Kolymbas, D. (2015). Introduction to barodesy. Géotechnique $\mathbf{6 5}$, No. 13, 52-65, https://doi.org/10.1680/geot.14.P.151.

Kolymbas, D. \& Medicus, G. (2016). Genealogy of hypoplasticity and barodesy. Int. J. Numer. Anal. Methods Geomech. 40, No. 18, 2532-2550, https://doi.org/10.1002/nag.2546.

Krey, H. (1927). Rutschgefährliche und fließende Bodenarten. Bautechnik 5 (in German).

Lancellotta, R. (2009). Geotechnical engineering, 2nd edn. London, UK: CRC Press, https://doi.org/10.1201/9781482265934.

Mašín, D. (2005). A hypoplastic constitutive model for clays. Int. J. Numer. Anal. Methods Geomech. 29, No. 4, 311-336.

Mašín, D. (2012a). Asymptotic behaviour of granular materials. Gran. Matter 14, 759-774, https://doi.org/10.1007/s10035-0120372-x.

Mašín, D. (2012b). Hypoplastic Cam-clay model. Géotechnique 62, No. 6, 549-553, https://doi.org/10.1680/geot.11.T.019.

Mašín, D. (2013). Clay hypoplasticity with explicitly defined asymptotic states. Acta Geotech. 8, No. 5, 481-496, https://doi. org/10.1007/s11440-012-0199-y.

Mašín, D. (2019). Modelling of soil behaviour with hypoplasticity another approach to soil constitutive modelling. Springer Series in Geomechanics and Geoengineering. Cham, Switzerland: Springer International Publishing.

Mašín, D. \& Herle, I. (2005). State boundary surface of a hypoplastic model for clays. Comput. Geotech. 32, No. 6, 400-410, https://doi.org/10.1016/j.compgeo.2005.09.001.

Medicus, G. (2015). Barodesy and its application for clay. No. 20. In Advances in geotechnical engineering and tunnelling. Berlin, Germany: Logos Verlag.
Medicus, G. \& Fellin, W. (2017). An improved version of barodesy for clay. Acta Geotech. 12, No. 2, 365-376, https://doi.org/ 10.1007/s11440-016-0458-4.

Medicus, G., Fellin, W. \& Kolymbas, D. (2012). Barodesy for clay. Géotech. Lett. 2, No. 4, 173-180, https://doi.org/10.1680/ geolett.12.00037.

Medicus, G., Kolymbas, D. \& Fellin, W. (2016). Proportional stress and strain paths in barodesy. Int. J. Numer. Anal. Methods Geomech. 40, No. 4, 509-522, https://doi.org/10.1002/nag.2413.

Nakai, T. (2007). Modeling of soil behavior based on $t_{i j}$ concept. In Proc. of 13th ARCSMGE, Kolkata, India, vol. 2, pp. 69-89, keynote paper.

Parry, R. (1960). Triaxial compression and extension tests on remoulded saturated clay. Géotechnique 10, No. 4, 166-180, https://doi.org/10.1680/geot.1960.10.4.166.

Pedroso, D. M., Farias, M. M. \& Nakai, T. (2005). An interpretation of subloading $t_{i j}$ model in the context of conventional elastoplasticity theory. Soils Found. 45, No. 4, 61-77, https://doi. org/10.3208/sandf.45.4_61.

Potts, D. M. \& Zdravković, L. (1999). Finite element analysis in geotechnical engineering. London, UK: Thomas Telford. https://doi.org/10.1680/feaiget.27534.

Rauter, M., Barker, T. \& Fellin, W. (2020). Granular viscosity from plastic yield surfaces: the role of the deformation type in granular flows. submitted to Computers and Geotechnics.

Roscoe, K. H., Schofield, A. N. \& Wroth, C. P. (1958). On the yielding of soils. Géotechnique 8, No. 1, 22-53, https://doi.org/10.1680/geot.1958.8.1.22.

Schaeffer, D. G. (1987). Instability in the evolution equations describing incompressible granular flow. J. Differ. Equ. 66, No. 1, 19-50, https://doi.org/10.1016/0022-0396(87)90038-6.

Shi, X. S., Herle, I. \& Bergholz, K. (2017). A nonlinear Hvorslev surface for highly overconsolidated soils: elastoplastic and hypoplastic implementations. Acta Geotech. 12, No. 4, 809-823, https://doi.org/10.1007/s11440-016-0485-1.

Tiedemann, B. (1937). Über die Schubfestigkeit bindiger Böden. Bautechnik 15 (in German).

Topolnicki, M., Gudehus, G. \& Mazurkiewicz, B. (1990). Observed stress-strain behaviour of remoulded saturated clays under plane strain conditions. Géotechnique 40, No. 2, 155-187, https://doi.org/10.1680/geot.1990.40.2.155.

Wood, D. M. (1990). Soil behaviour and critical state soil mechanics. Cambridge, UK: Cambridge University Press. 